\title{
Review of Methods to Reduce Energy Consumption in A Smart City Based On IoT and 5G Technology
}

\author{
https://doi.org/10.3991/ijoe.v17i08.23671 \\ Julieta Evangelina Sánchez-Cano ${ }^{1}$, Washington Xavier García-Quilachamin²(凶), \\ Jonny Pérez-Véliz ${ }^{2}$, Jorge Herrera-Tapia ${ }^{2}$, Kelvin Atiencia Fuentes ${ }^{2}$ \\ ${ }^{1}$ Universidad Juárez del Estado de Durango, Dgo, México \\ ${ }^{2}$ Universidad Laica Eloy Alfaro de Manabí, Manta, Ecuador \\ profegarcia501@gmail.com
}

\begin{abstract}
The evolution of the technology 5G has influenced the Internet of the Things (IoT) according to the wireless communications of minor latency, and major speed compared to the existing technologies. Consequently, from the $21 \mathrm{st}$ century, $5 \mathrm{G}$ will act as the spinal column of the IoT and will level the way for the design and deployment of a Smart City, nevertheless, this progress has a negative point which is demonstrated in the energy consumption. The target of this investigation is to announce methods to reduce the consumption of energy in one Smart City based on the IoT and the technology 5G. The results obtained in this investigation allow determining that $5 \mathrm{G}$ and the IoT will have a major energy consumption with about $80 \%$ of the entire potency, due to the transmission and reception of a big quantity of information in a Smart City. Likewise, this research, contribute to the knowledge, presenting a review of methods that allow minimizing energy consumption and projects that improve energy efficiency.
\end{abstract}

Keywords-5G technology, IoT, Smart City, energy consumption

\section{Introduction}

There is a great interest in new applications especially for fifth generation technology (5G) according to [1], the authors explain that this has a great improvement due to its lower latency and greater coverage in scenarios such as the IoT and the Smart City. The internet of Things (IoT) refers to the coordination of various machines, devices and applications connected to the Internet through multiple wired or wireless networks as explained in [2]. According to [3], many IoT devices can be used for different applications within Smart City, allowing the exchange of information and communication within the city, improving the quality of life of its citizens. This shows that IoT and the $5 \mathrm{G}$ network have been introduced to improve sustainability and speed within the environment of a Smart City. According to the authors Sofí and Gupta [4], the exponential growth of devices, objects and sensors connected to 5G technology and the IoT are constantly increasing the demand for energy, with an unprecedented growth in wireless data services, which causes battery drain issues for wireless nodes/devices. 
Likewise, the authors of [5] specify that this is due to the fact that several devices are forming an ultra-dense network, so the need to improve energy efficiency must be paramount to face the exponential increase in energy consumption. This has been planned in different types of methods, considering a multitier architecture to make the network fast and energy-friendly [6]. This document presents methods that focus on reducing energy consumption in relation to $5 \mathrm{G}$ technology, IoT and Smart City, as well as projects that have been implemented in different countries to minimize the amount of energy consumption [7].

The objective of this research is to present methods to reduce energy consumption in a Smart City based on IoT and 5G technology, in addition to the applications that are used with $5 \mathrm{G}$ technology and IoT. Therefore, the following questions are raised that allow us to obtain information related to our objective and whose answers inform the process developed in relation to the methods to reduce energy consumption: Q1) How would 5G technology and IoT affect energy consumption in a Smart City? Q2) What are the applications that use 5G in a Smart City with IoT? and Q3) Are there methods to reduce energy consumption in a Smart City provided by the $5 \mathrm{G}$ network in the IoT?

This document is organized as follows, in Section 2 the materials and methods related to the subject of our research are presented. Section 3 describes the results found by answering the questions in the previous section. Section 4 focuses on the analysis of the results obtained on 5G technology and its relationship with energy consumption in IoT applied in a Smart City. In the last section, there are the conclusions of the investigation and finally the references.

\section{$2 \quad$ Materials and methods}

A systematic review of the literature was developed in three main processes, considering the criteria stated by the authors [8] and the suggestions used by [9]. The established criteria are the following: Research planning, development of the search for information, and results found.

\subsection{Information search}

To achieve our purpose, the following research questions were developed: Q1: How would 5G technology and the IoT affect energy consumption in a Smart City? Q2: What are the applications that use 5G in a Smart City with IoT? and, Q3: Are there methods to reduce energy consumption in a Smart City provided by the $5 \mathrm{G}$ network in the IoT?

Inclusion and exclusion criteria were also considered in this study. The following are considered as basic inclusion criteria: articles that are available in full text in journals and books, articles can be from a literature review and/ or systematic review, articles related to research questions, the search range for articles from 2017 to the year 2021 .

For the exclusion criterion, articles that do not meet the inclusion criteria are excluded. In the search chain, the protocols were defined considering the author [9], the information sources were selected and the search strategy was created. For this, the following keywords were used: Technology 5G, Energy Consumption, IoT, Smart City and the logical relationship was established using the AND operator, as described below: 5G technology to energy 
consumption in the IoT in a Smart City with IoT, methods to reduce energy consumption in a Smart City provided by the $5 \mathrm{G}$ network in the IoT.

In Figure 1, the criteria established in this investigation were considered. The information search process was carried out by applying the search string to each of the data sources and, as a result, a total of 1734 articles were obtained.

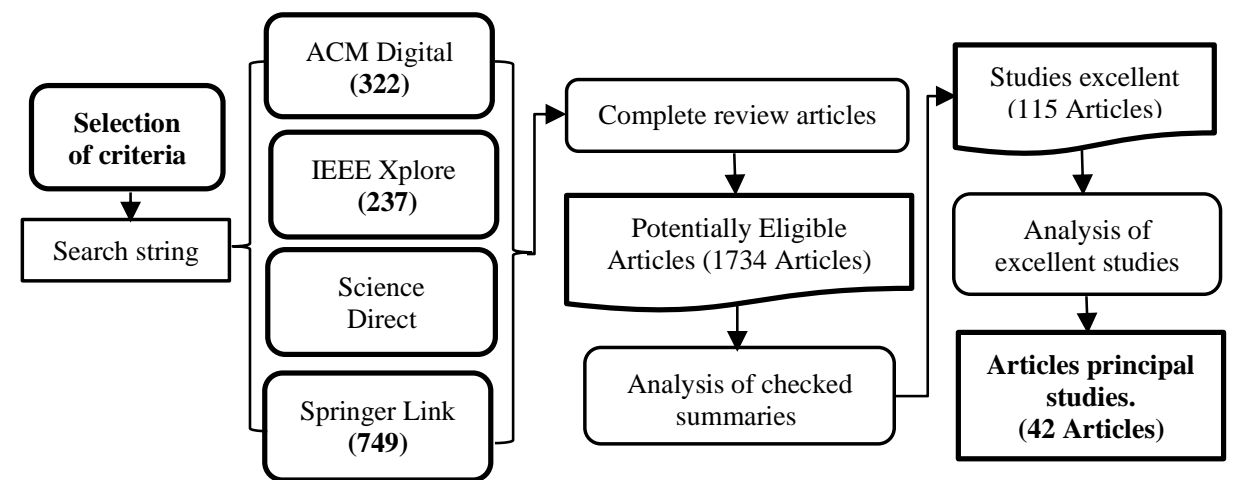

Fig. 1. Process of search

\subsection{Search results}

A review and depuration of articles that did not meet the established criteria or that were duplicated in different sources of information was carried out. Subsequently, the articles found were reviewed and a total of 1734 research papers were eliminated, obtaining 115 relevant studies of this process, from which the full content of each of these articles was reviewed, obtaining 42 main studies and their analysis. See Figure 2 .

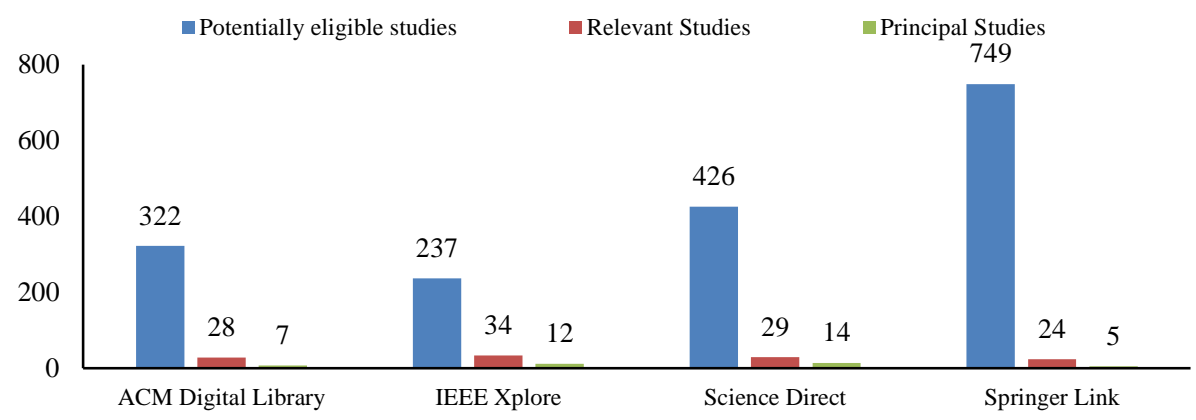

Fig. 2. Search results 


\section{Results}

The results found are described based on the established questions, instructing on 5G technology, its evolution and parameters (advantages and disadvantages), in addition, the IoT and its relationship with 5G and the Smart City are described, as well as on the concept and architecture of a Smart City and applications that use 5G in a Smart City with IoT, then, the energy consumption caused by $5 \mathrm{G}$ technology and the IoT in a Smart City is described and at the end a review is indicated on methods and projects to reduce energy consumption in a Smart City.

\subsection{Technology 5G}

$5 \mathrm{G}$ technology is the fifth generation of wireless communication, which will be used by devices to connect to the Internet from anywhere. By using MIMO antenna systems (Multiple input, Multiple output) in order to meet the demands of businessmen, consumers and the needs of new use cases [5]. According to Monta and Brice [10], 5G technology is considered a technological evolution, which increases coverage, capacity, and transmission speed, that is, it can reach a large number of connected devices at the same time.

5G evolution. According to the authors [10], 5G is a new proposal that will use a single universal device to interconnect all existing communication infrastructures to provide all possible applications. In other words, it is the evolution of the connectivity of different generations of networks shown in Figure 3 that has completely changed communication and led us to a new realm of hyper-connectivity.

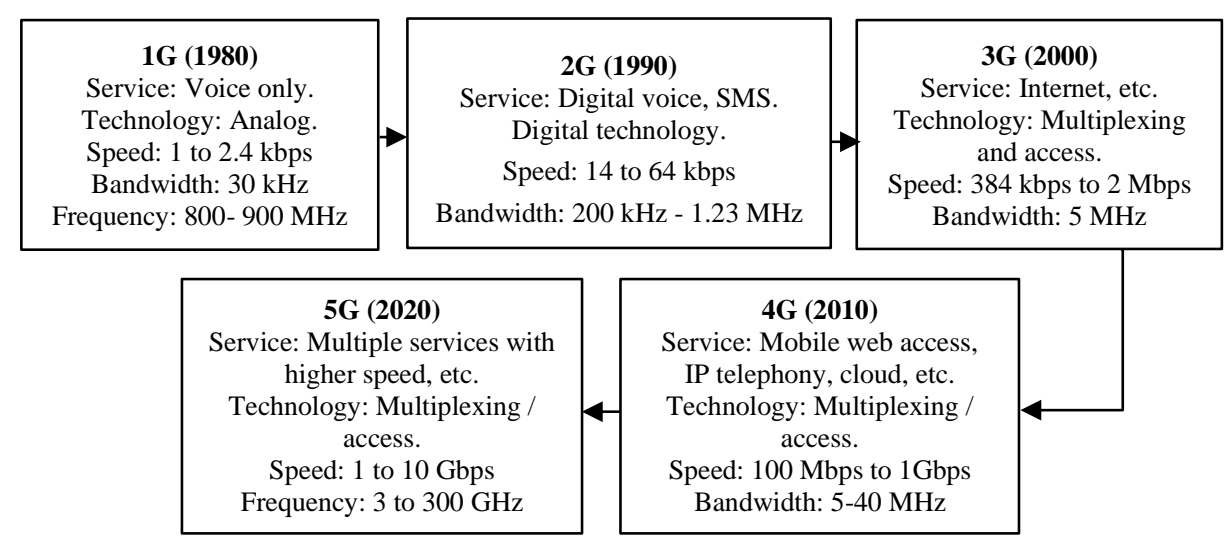

Fig. 3. Evolution of network technology

With the evolution of $5 \mathrm{G}$, it is predicted that adoption will be much more accelerated than that of the previous generation $(4 \mathrm{G})$, where it is indicated that in 2025 the number of global subscriptions could even exceed 2,726 billion [1], see Figure 4. Most of them would be from Asia and Oceania with 1.823 trillion, while approximately 421 trillion and 305 trillion would be in Europe and North America, respectively. 
Parameters (Advantage - Disadvantage) The diversity of technology and infrastructure changes inherent in the implementation of 5G technology has brought enormous benefits and potential challenges for every user, business, and service provider. Tables 1 and 2 describe the most relevant 5G parameters, indicating their advantages and disadvantages.

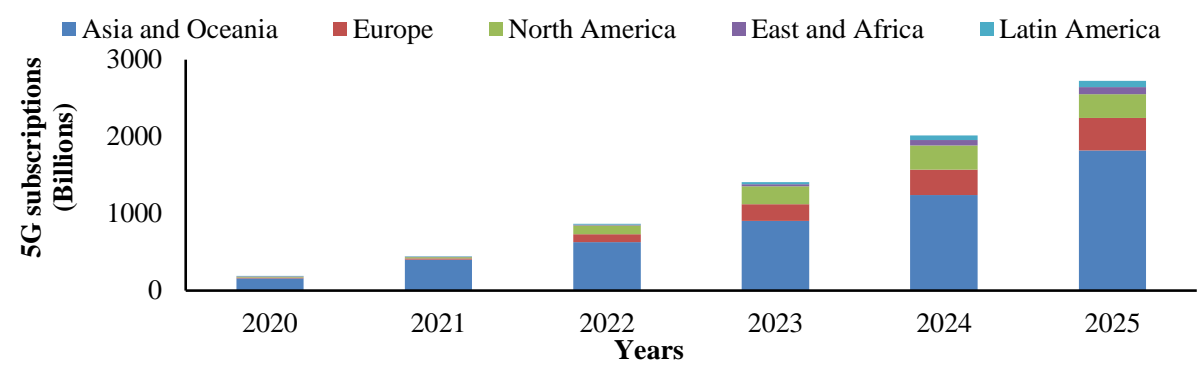

Fig. 4. Adoption of $5 \mathrm{G}$ in 2025

Table 1. 5G Technology advantage

\begin{tabular}{|l|l|l|c|}
\hline \multicolumn{1}{|c|}{ Parameters } & \multicolumn{1}{|c|}{ Description } & \multicolumn{1}{c|}{ Advantage's ratio } & Ref. \\
\hline Speed & $\begin{array}{l}\text { Speed with which data is transmit- } \\
\text { ted through the media. }\end{array}$ & $\begin{array}{l}\text { It has an advantage and data transfer speed of } \\
10 \mathrm{Gbps} .\end{array}$ & $\begin{array}{c}{[11] ;} \\
{[2]}\end{array}$ \\
\hline Latency & $\begin{array}{l}\text { Geographical scope to which it } \\
\text { provides network connectivity. }\end{array}$ & $\begin{array}{l}\text { It presents an advantage and more devices } \\
\text { connected at the same time; it will guarantee } \\
100 \% \text { coverage. }\end{array}$ & {$[12]$} \\
\hline $\begin{array}{l}\text { Network } \\
\text { coverage }\end{array}$ & $\begin{array}{l}\text { Time it takes for a packet to be } \\
\text { transmitted from one point to } \\
\text { another. }\end{array}$ & $\begin{array}{l}\text { It has an advantage and Low latency of 1 to 5 } \\
\text { milliseconds in transmission. }\end{array}$ & {$\left[\begin{array}{c}{[13] ;} \\
{[10]}\end{array}\right.$} \\
\hline
\end{tabular}

Next, Table 2 indicates the relevant disadvantages of the $5 \mathrm{G}$ network.

Table 2. 5G technology disadvantages

\begin{tabular}{|l|l|l|c|}
\hline \multicolumn{1}{|c|}{ Parameters } & \multicolumn{1}{|c|}{ Description } & \multicolumn{1}{c|}{ Disadvantage's ratio } & Ref. \\
\hline $\begin{array}{l}\text { Energy con- } \\
\text { sumption }\end{array}$ & $\begin{array}{l}\text { It is the amount of energy that is } \\
\text { consumed in the different devices. }\end{array}$ & $\begin{array}{l}\text { It has a disadvantage since the power con- } \\
\text { sumption of a 5G base station is triple that of } \\
\text { 4G. }\end{array}$ & {$\left[\begin{array}{l}{[4] ;} \\
{[14]}\end{array}\right.$} \\
\hline Infrastructure & $\begin{array}{l}\text { It is the means that allows you to } \\
\text { connect to wired and wireless } \\
\text { networks. }\end{array}$ & $\begin{array}{l}\text { It has a disadvantage and requires new infra- } \\
\text { structure and the cost of 5G infrastructure is } \\
\text { high. }\end{array}$ & {$[15]$} \\
\hline $\begin{array}{l}\text { Security and } \\
\text { privacy }\end{array}$ & $\begin{array}{l}\text { They are protection measures to } \\
\text { prevent unauthorized access to } \\
\text { data. }\end{array}$ & $\begin{array}{l}\text { It presents a disadvantage to cyber-attacks } \\
\text { because more devices are connected to the } \\
\text { network. }\end{array}$ & $\begin{array}{c}{[11] ;} \\
{[1]}\end{array}$ \\
\hline
\end{tabular}




\subsection{Internet of things (IoT)}

The Internet of Things refers to a system of physical devices that can receive and transmit data over a wireless network without human intervention, which is changing the way service providers interact with customers, according to the authors of [2].

According to the authors [15] the IoT will create an ultra-connected world, where the various applications of 5G technology could lead to a more varied offer of services as indicated in Figure 5, there will be from, cars, homes, workplaces and cities will use sensors entirely, with countless uses.

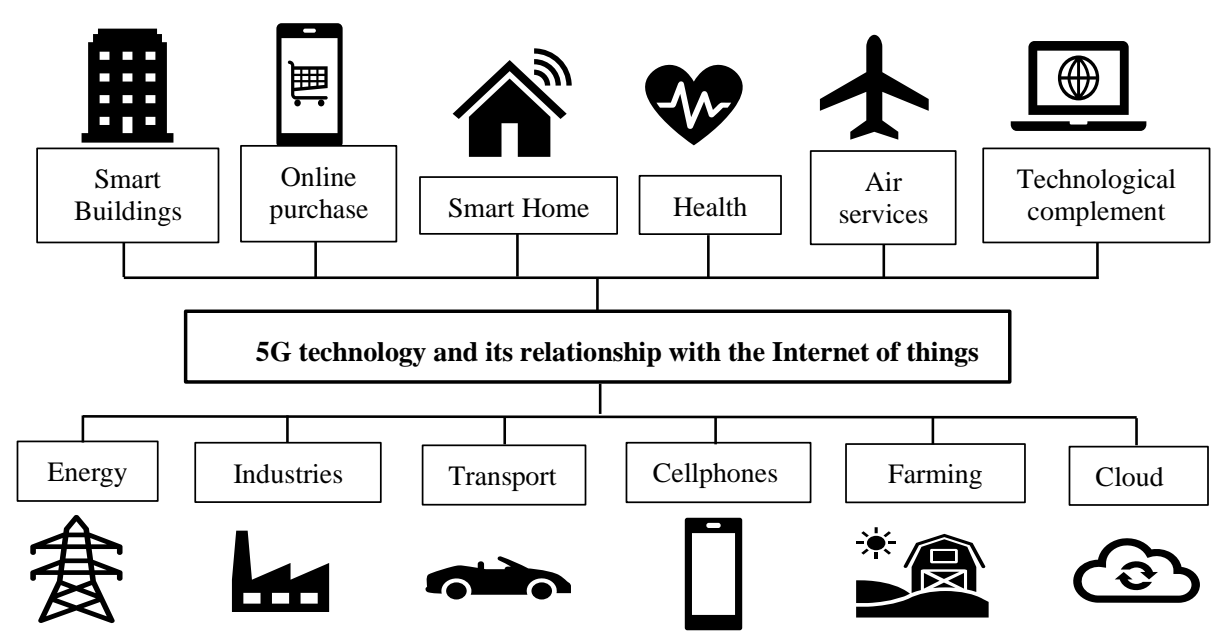

Fig. 5. 5G technology and IoT applications

IoT in relation to a Smart City. The IoT is the most important and significant component part of most smart city applications, which are responsible for generating an immense amount of data [16].

In the presence of such large and complex amounts of data, it is difficult to decide precisely the most precise and efficient actions [17]. The best possible Big Data analysis can be carried out using advanced techniques such as Artificial Intelligence (AI), Machine Learning (ML) and Deep Reinforcement Learning (DRL) to reach an optimal decision. Furthermore, the internet of Things (IoT) basically connects any device to the internet and controls its functions through Internet commands [13].

Technology 5G in a Smart City with IoT. The use of IoT devices applied in a Smart City, has brought challenging requirements, especially in terms of greater bandwidth, mobility and reduced latency, therefore, the use of 5G technology is essential to meet the demands of the IOT in a Smart City [18]. Therefore, to make the smart city and IoT reality, the use of fifth generation technology $(5 \mathrm{G})$ is essentially necessary to cope with the demands of massive data and high-speed communications in Smart Cities, according to the authors of [19]. 


\subsection{Smart City}

A Smart City according to Rao and Prasad [11] is considered an innovative city that uses a variety of technologies and other means to improve the efficiency of the city's operations and services, thus improving the quality of life of the citizens and ensuring economic, social and environmental sustainability.

The main objective of a Smart City is to use the advanced information and communication functions of the telecommunications infrastructure to achieve efficient management of resources, functions that require a perfect connection between the different components and users that make up the city's infrastructure [20].

Application architecture. A generalized architecture of applications of a Smart City, composed by environment detection, communication protocols, data transmission and security and privacy [21]. The importance of the security plan in Smart City applications is clearly shown in Figure 6.

\section{SECURITY AND PRIVACY PLAN}

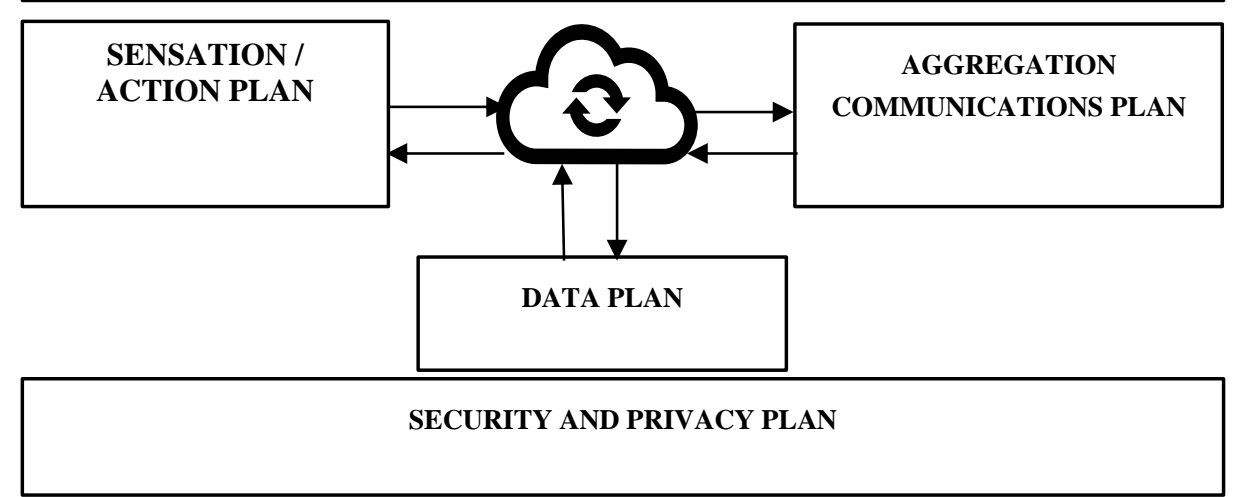

Fig. 6. Architecture of a smart city

Applications that use 5G in a Smart City with IoT. Rao and Prasad mention [11], that in Smart Cities, it is very important to improve the living standards of residents by improving the city's infrastructure, traffic management, governance, water and waste management, energy management, the health system, the security system, the education system, etc.

On other hand, the authors [20] state that IoT applications will accommodate a wide range of use cases, in particular the application in a Smart City, which involves many services of daily life, including intelligent transports systems, telemedicine, environmental monitoring, security monitoring, social media, e-business, etc.

Next, Table 3 describes applications of a Smart City, which can be enabled or delivered more efficiently through $5 \mathrm{G}$ and the IoT. 
Table 3. Applications using $5 \mathrm{G}$ in a Smart City with IoT.

\begin{tabular}{|l|l|l|}
\hline \multicolumn{1}{|c|}{ Applications } & \multicolumn{1}{|c|}{ Summary } & Ref. \\
\hline Smart Home & $\begin{array}{l}\text { With 5G it allows the communication network of a Smart Home to be faster } \\
\text { send with lower latency in the different devices that allows them to be con- } \\
\text { trolled, monitored and accessed remotely to achieve better comfort. }\end{array}$ & $\begin{array}{l}{[11],} \\
{[22],} \\
{[23],} \\
{[24]}\end{array}$ \\
\hline Health & $\begin{array}{l}\text { 5G technology applied to healthcare aims to lower hospitalization rates by } \\
\text { remotely monitoring patients in their own homes. In addition, it will connect the } \\
\text { entire network of emergency services. }\end{array}$ & $\begin{array}{l}{[3],} \\
{[25]}\end{array}$ \\
\hline $\begin{array}{l}\text { Transport } \\
\text { vehicles }\end{array}$ & $\begin{array}{l}\text { With 5G, vehicles will be able to detect critical safety situations, such as acci- } \\
\text { dents and other dangerous road conditions. In addition, to control remotely or } \\
\text { taking control of driving. }\end{array}$ & $\begin{array}{l}{[11],} \\
{[19]}\end{array}$ \\
\hline $\begin{array}{l}\text { Security and } \\
\text { surveillance } \\
\text { systems }\end{array}$ & $\begin{array}{l}\text { The 5G allows the integration of being able to observe through video in real } \\
\text { time with access to specific locations. This would allow facial recognition to } \\
\text { detect known criminals or spot a person in a crowd. }\end{array}$ & $\begin{array}{l}{[11],[1} \\
9]\end{array}$ \\
\hline Street lighting & $\begin{array}{l}\text { 5G technology enables devices and sensors on the street to track pedestrians or } \\
\text { vehicles in real time and lower street lighting during times when there are no } \\
\text { pedestrians or vehicles on the street. }\end{array}$ & {$[19]$} \\
\hline $\begin{array}{l}\text { Traffic man- } \\
\text { agement }\end{array}$ & $\begin{array}{l}\text { 5G allows monitoring the flow of traffic through sensors. Vehicle navigation } \\
\text { systems will go a step further to avoid the driver on routes with heavy traffic and } \\
\text { inform them of free parking spaces in the cities. }\end{array}$ & {$[11]$} \\
\hline
\end{tabular}

\subsection{Energy consumption}

Energy consumption with the 5G technology. This new 5G technology standard is particularly intensive in use and energy consumption, that is, smart phones require more battery consumption and the power consumption of base stations also triples, according [1]. At the same time, the construction of networks that support this demand for new services has resulted in a growing increase in energy consumption, as indicated in Figure 7, and according to the author Joshi [26], he considers it as a higher power consumption compared to previous networks.

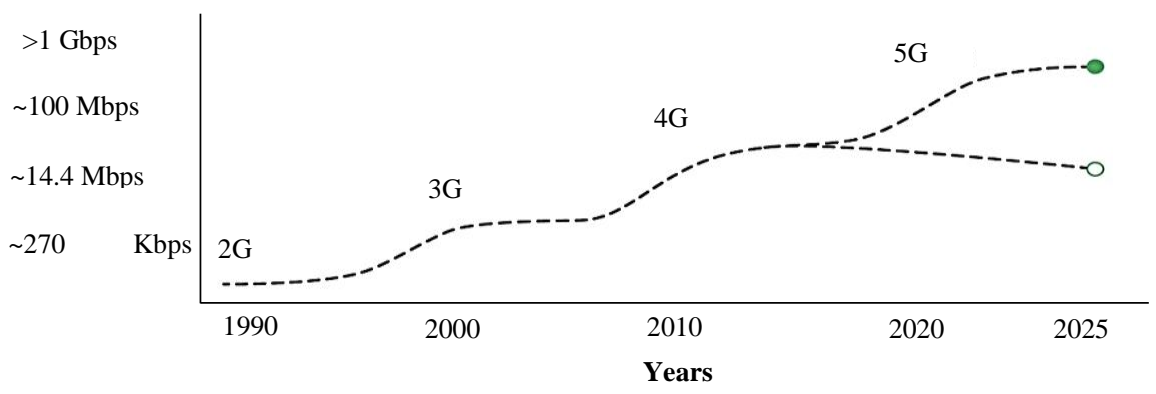

Fig. 7. 5G energy efficiency

The energy consumption of a mobile network is dominated by Base Stations (BS), which currently consume around $80 \%$ of the total power [27]. However, the authors of [5] guarantee that this increase in consumption will not significantly affect the autonomy of devices such as mobiles or tablets, but it will affect what is related to the 
IoT and the sensors that have to transmit a large amount of constant information and are not connected to the electrical grid.

Hence, 5G technology will be significantly more energy intensive than previous generations of wireless connectivity. 5G technology will likely increase total grid power consumption by $150 \%$ to $170 \%$ by 2026 , according to [28]. This study estimates that by 2030 information technology will consume a fifth of all the world's electricity. Which means a challenge at the energy level; therefore, the supply must grow in the face of a strong increase in the demand for electricity.

Energy consumption in the IoT. According the authors of [14], it is estimated that by 2025 the subscriptions to the IOT will have increased to billions of users, as indicated in Figure 8. Consequently, this event has an exponential consumption of energy for detection of devices, including registration, routing, etc., this will quickly deplete the node's resources, which can further affect the entire network and power consumption to meet the requirements of the IoT.

Devices in IoT are operable in continuous mode, so the total amount of power consumption tends to be too high, according to the authors [14], it is considered that there are power failures for the nodes that operate on the battery that lead to a large number un a network, because the massive reception of data requires efficient processing, which comes at the cost of a higher consumption of energy resources.

The massive increase in connected devices that make up a fully formed IoT is likely to require grater energy efficiency, according to [15]. Therefore, the IoT network must carefully address the problem of power consumption in order to extend the life of IoT devices and improve their ease of use on the network [29].

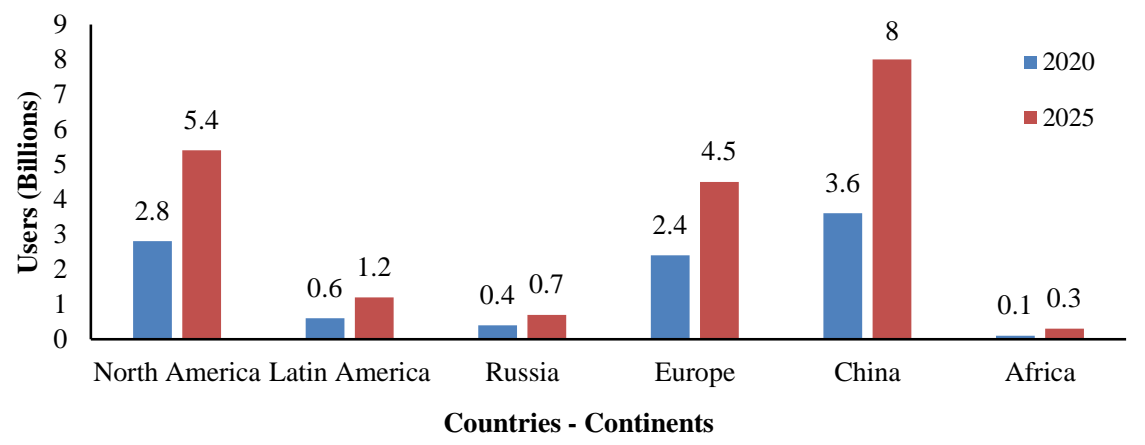

Fig. 8. Connections and subscribers in the IoT

Energy consumption in the Smart City. For the authors [30], they highlight that the main challenges of Smart City go through the management of energy power based on models that consider energy efficiency, as it is a key tool for the development of household production processes, companies and industries. Although they only occupy $2 \%$ of the earth's surface, they consume $75 \%$ of the world's energy and generate $80 \%$ of greenhouse gases.

Smart Cities are consumers of a large number of different types of energy. The energy distribution is provided through urban energy networks, which are complex structures and 
include a large number of elements. The main problem with energy systems is that the need for energy changes increasingly over the time, and changes mainly in a jump [25]. However, unfortunately, active management of energy consumption in Smart Cities is still at a very low level. In addition, the additional consumption of the IoT in the networks, and sensors, among others that are applied in the public lighting of a city that turn on and off automatically, depending on the level of natural light. However, a large number of energy consumers, especially in the residential sector, are not yet ready for active management. Currently, they operate independently, which creates very big problems for power grids [32]. Total energy consumption is at least $14 \%$ of total electricity consumption in the residential sector of cities.

The authors Nematchoua, Orosa and Reiter [6] developed an assessment of energy consumption due to the mobility of the habitants and a multi-year prospective in the horizon from 2030 to 2050 in a city in Belgium. In Table 4, the data obtained from the analysis of the selected activities and parameters are presented.

Table 4. Energy consumption by type of day.

\begin{tabular}{|c|c|c|c|}
\hline Year & Parameters & Workdays $(\mathbf{k W h})$ & School workdays (kWh) \\
\hline \multirow{4}{*}{2030} & Passive assist & 4493.0 & 3170.0 \\
\cline { 2 - 4 } & Smart assistance & 392.9 & 277.2 \\
\cline { 2 - 4 } & Carbon creativity & 2908.6 & 2263.5 \\
\cline { 2 - 4 } & New climate and energy infrastructures & 3571.8 & 2520.0 \\
\cline { 2 - 4 } & Continuous city & 3007.9 & 1895.3 \\
\cline { 2 - 4 } & Sober urbanity & 2840.8 & 1790.0 \\
\hline \multirow{4}{*}{2050} & Passive assist & 4989.0 & 3520.0 \\
\cline { 2 - 4 } & Smart assistance & 82.3 & 58.1 \\
\cline { 2 - 4 } & Carbon creativity & 1600.0 & 1128.8 \\
\cline { 2 - 4 } & New climate and energy infrastructures & 1928.3 & 1360.5 \\
\cline { 2 - 4 } & Continuous city & 1508.9 & 1064.6 \\
\cline { 2 - 4 } & Sober urbanity & 1508.9 & 1064.6 \\
\hline
\end{tabular}

\subsection{Methods found to reduce energy consumption in a Smart City}

In an attempt to overcome energy consumption limitations, current possible solutions related to energy efficiency are presented. In Table 5 shows the methods that have been implemented to reduce energy consumption.

Table 5. Methods to reduce energy consumption.

\begin{tabular}{|l|l|l|}
\hline \multicolumn{1}{|c|}{ Methods } & \multicolumn{1}{|c|}{ Abstract } & Ref. \\
\hline Harvesting energy & $\begin{array}{l}\text { Mechanism that allows devices to charge their batteries by collecting surplus } \\
\text { electromagnetic energy from the environment. }\end{array}$ & {$[33]$} \\
\hline $\begin{array}{l}\text { Harvest and } \\
\text { energy transfer }\end{array}$ & $\begin{array}{l}\text { Energy is harvested from natural resources such as the sun and wind, and also } \\
\text { from radio frequency signal that offers incredible chances of diminishing the } \\
\text { wireless energy source. }\end{array}$ & $\begin{array}{l}{[34],} \\
{[35]}\end{array}$ \\
\hline Spectrum ex- & Spectrum sharing can improve spectrum efficiency by allowing more than one & {$[36]$,} \\
\hline
\end{tabular}


Paper-Review of methods to reduce energy consumption in a Smart City based on IoT and 5G

\begin{tabular}{|l|l|l|}
\hline \multicolumn{1}{|c|}{ Methods } & \multicolumn{1}{|c|}{ Abstract } & Ref. \\
\hline change & node to use similar spectrum in the meantime. & {$[37]$} \\
\hline $\begin{array}{l}\text { DTX mode (dis- } \\
\text { continuous trans- } \\
\text { mission) }\end{array}$ & $\begin{array}{l}\text { It is used to reduce the power consumption of a base station by switching to } \\
\text { leep mode for small periods in each frame. }\end{array}$ & $\begin{array}{l}{[38],} \\
{[39]}\end{array}$ \\
\hline $\begin{array}{l}\text { Massive MIMO } \\
\text { network }\end{array}$ & $\begin{array}{l}\text { Massive MIMO systems are what allow us to reduce the transmitted power. } \\
\text { The transmitting power from the terminals will expand the backup battery. }\end{array}$ & $\begin{array}{l}{[34],} \\
{[40],} \\
{[41]}\end{array}$ \\
\hline $\begin{array}{l}\text { Multi-beam } \\
\text { carriers (MBCA). }\end{array}$ & $\begin{array}{l}\text { Mechanism to reverse the extend of bandwidth accessible to users in the 5G } \\
\text { wireless communication network. }\end{array}$ & {$[42]$} \\
\hline Cells zoom & $\begin{array}{l}\text { Some BS can be turned off if traffic is low, while others establish cover holes } \\
\text { by increasing their power. }\end{array}$ & {$[4]$} \\
\hline
\end{tabular}

\subsection{Projects to reduce energy consumption in a Smart City}

At the time, different countries develop new solutions to minimize energy consumption, in this way, the distribution network can reduce dependence on the main network, increase the efficiency of energy use and also reduce energy costs for users, state authors of [7]. Next, Table 6 shows different countries where projects focused on solving the energy efficiency caused by the IoT and $5 \mathrm{G}$ technology have been carried out.

Table 6. Project application as a solution for energy reduction.

\begin{tabular}{|l|l|c|c|c|}
\hline \multirow{2}{*}{ Country } & \multicolumn{1}{|c|}{ Projects - System description } & \multicolumn{1}{|c|}{ Application } & \multirow{1}{*}{ Ref. } \\
\cline { 2 - 3 } Finland & $\begin{array}{l}\text { WIVE Project, focuses uRLLC and mMTC features of 5G to } \\
\text { achieve remote control of machines with low latency. As a goal of } \\
\text { verifying its energy efficiency. }\end{array}$ & yes & yes & [7] \\
\hline \multirow{2}{*}{ Australia } & $\begin{array}{l}\text { VPP Project, the batteries will supply power for short periods of } \\
\text { time when the maximum load occurs. To update smat grids and } \\
\text { IoT applications. }\end{array}$ & yes & yes & [7]; \\
\hline \multirow{2}{*}{$\begin{array}{l}\text { Europe } \\
\text { Continent }\end{array}$} & $\begin{array}{l}\text { VirtuWind Project, based on } \\
\text { 5G NF and SDN technologies, can simultaneously reduce the } \\
\text { amount of hardware and power to make the control of wind farms } \\
\text { faster. }\end{array}$ & yes & yes & [7]; \\
\hline \multirow{2}{*}{ China } & $\begin{array}{l}\text { SG-eIoT System, equipped with efficient information processing } \\
\text { functions and to accelerate the construction of smart homes with- } \\
\text { out increasing energy consumption. }\end{array}$ & yes & yes & [43] \\
\hline
\end{tabular}

The VPP (Virtual Electric Plants) project is a system that integrates software and an intelligent electrical grid to dispatch and optimize DER (Distributed Energy Resources), through an aggregation and optimization platform remotely and automatically. VPPs can be cloud-based, centralized, or distributed platforms that aggregate, optimize, and control varied and heterogeneous DERs to behave like conventional dispatchable power plants; that is, the VPPs deliver energy without necessarily having a physical plant. The goal of a VPP is to alleviate the load on the grid by intelligently managing the power generated in a distributed manner during peak load periods.

However, although the current use of demand response systems is limited, Australia has the necessary infrastructure to implement this type of systems, by 2024 Austral- 
ia will be the world leader in the number of homes, buildings and companies that install their own power supply and disconnect from the network, see Fig. 9 thus improving the energy efficiency of the wireless network.

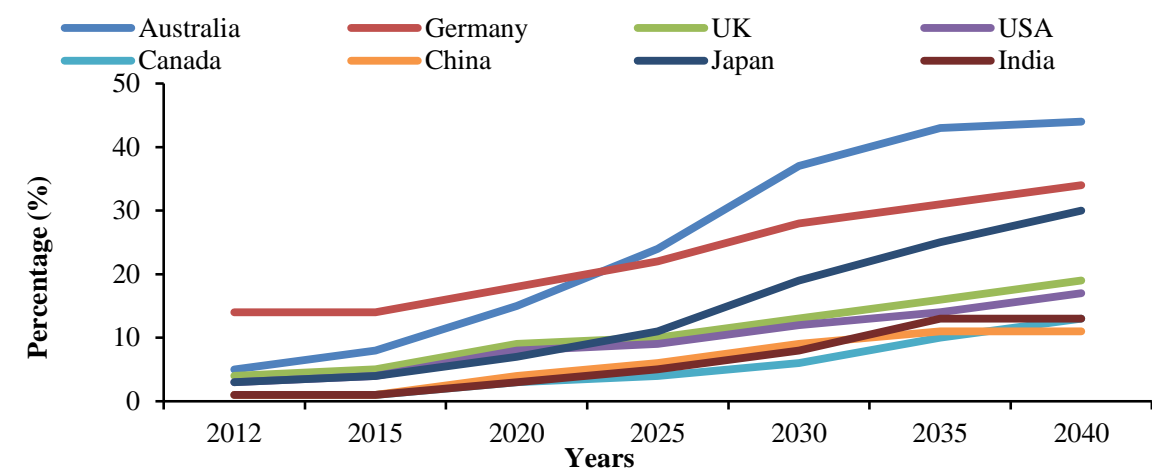

Fig. 9. Relationship between electricity capacity and total installed.

Currently a VPP project is being carried out in South Australia (SA) led by the American company Tesla, this will make this system the largest VPP in the world. The project (800 million AUD) will have 250 (MW) of capacity and 650 (MWh) of storage, which will allow pooling of resources to help provide grid stability, as well as additional capacity when there is a supply shortage. The first stage of VPP has now been completed, with 100 homes totaling $500(\mathrm{~kW})$ and $1.350(\mathrm{kWh})$ and has already demonstrated a key advantage of VPP: they can start supplying electricity from early stages, unlike conventional power plants, that can only begin to operate once construction is completed [44].

Households that participated in phase I of the initiative have seen a $70 \%$ reduction in their consumption of electricity from the grid. Consequently, the project has already started the second stage, which covers 1,000 homes increasing the capacity to $5.5(\mathrm{MW})$ and $14.85(\mathrm{MWh})$. The companies of VPP project and response to electricity demand are presented below, see Table 7 .

Table 7. VPP projects and response to electrical demand.

\begin{tabular}{|l|l|c|c|}
\hline Company & \multicolumn{1}{|c|}{ Description } & $\begin{array}{c}\text { Maximum } \\
\text { capacity }\end{array}$ & $\begin{array}{c}\text { Financing } \\
\text { (Million AUD) }\end{array}$ \\
\hline AGL & $\begin{array}{l}\text { 17 MW of capacity (from industrial costumers) y 3 MW (from } \\
10.000 \text { households) to starting from demand response systems } \\
\text { and controllable storage. }\end{array}$ & $20 \mathrm{MW}$ & 5,2 \\
\hline $\begin{array}{l}\text { Energy } \\
\text { Australia }\end{array}$ & $\begin{array}{l}\text { Remote control and load reduction devices for aggregation } \\
\text { together with smart battery storage systems. }\end{array}$ & $20 \mathrm{MW}$ & 2,9 \\
\hline EnerNOC & $\begin{array}{l}\text { Hardware installation for automatic and remote control of the } \\
\text { use of energy in 30 industrial companies. The response to the } \\
\text { demand will proceed of load reduction. }\end{array}$ & $20 \mathrm{MW}$ & 3,6 \\
\hline $\begin{array}{l}\text { Flow } \\
\text { Power }\end{array}$ & $\begin{array}{l}\text { Program called Energy Under Control for the deployment of } \\
\text { its own smart controller for 100 commercial power customers } \\
\text { in NSW. }\end{array}$ & $20 \mathrm{MW}$ & 2,6 \\
\hline
\end{tabular}


In this way, Smart City can reduce energy consumption, and can also increase energy efficiency with the use of renewable energy and thus reduce energy costs for users, according to the authors of [38]. Also, small users in future power systems will have more DERs, energy storage batteries and flexible loads, which will be based on ubiquitous 5G and IoT networks, according to [5].

\section{$4 \quad$ Analysis}

\subsection{Analysis about how 5G technology and the IoT affect energy consumption in a Smart City}

Regarding the search based on Q1, it is described that 5G technology is a Wireless communication network with greater deployment and speed, therefore, they influence energy efficiency in an IoT considering the advantages and disadvantages described. In addition, the IoT receives and transmits data, allowing a wide variety of applications such as the Smart City to be used. In other words, the 5G network and the IoT will generate a great demand for large-scale connections and will have a very important impact on the network and especially on energy consumption.

In the case of $5 \mathrm{G}$, the base stations and device batteries are their main depletion demand, in the same way in the IoT it will affect the consumption in the sensors that have to transmit enough information constantly and are not connected to the network electrical.

\subsection{Analysis on the applications that use 5G in a Smart City with IoT}

With the results obtained on the Q2 we find several important applications and services, which allow the use of various types of technology to contribute to the wellbeing and comfort of its inhabitants and consequently an improvement in the efficiency of the different activities through the IoT and 5G technology in a Smart City.

Seven applications are described that work efficiently with 5G and IoT technology, which improve speed and coverage, such as public lighting that is activated by sensors with the detection of pedestrians and vehicles. On the other hand, it also improves security and surveillance by obtaining videos in real time and access to locations. The results also allow us to determine that the IoT manages the different applications of a Smart City but considering that with $5 \mathrm{G}$ technology it is carried out at a higher speed and coverage.

\subsection{Analysis on the methods to reduce energy consumption in a Smart City provides by the $5 \mathrm{G}$ network in the IoT}

In relation to Q3. The problem of energy consumption in a Smart City caused by the IoT and 5G technology was analyzed, allowing us to find different methods that allow us to overcome the limitations of energy consumption. Therefore, seven methods are presented to reduce energy consumption, it is the case of energy collection 
that allows charging the batteries of the devices by collecting excess electromagnetic energy from the environment, we also have the Mode DTX that reduces consumption by changing to the mode of suspension for short periods.

In addition, four projects that are being carried out in different countries are presented, such as Australia, with the VPP project given as a procedure for reducing energy consumption, since they can collect data in real time to improve both the forecast and trade in different energy sources. Thus, having a $70 \%$ reduction in its consumption of electricity from the grid in phase 1 of the VPP project. Definitely, the implementation of methods and projects is very important to be able to obtain energy efficiency in a Smart City, due to the consumption that generates its highest performance to IoT and $5 \mathrm{G}$ technology.

\section{Conclusions}

This document describes 5G technology, which is considered important for the implementation of the Internet of Things communication model Based on the development of a Smart City. 5G technology will connect billions of devices through wireless networks, such as cars, appliances, machinery and technology. Also, in this study, innovative countries and regions were found that use Smart City technologies, through sensors and connected data, to provide public services effectively. In this way, 5G will improve the Internet of Things and allow the development of Smart City with greater communication efficiency.

The implementation of 5G technology and the IoT do increase energy demand, impacting upward energy consumption, which can have an impact to meet the requirements of a Smart City. Therefore, one of the main challenges of Smart City is how to increase energy efficiency and reduce total energy consumption, while maintaining the maximum comfort of citizens.

The purpose of this document is to review the methods and projects that allow solving the energy efficiency problem for the proper environment of a Smart City. Therefore, this study is concluded considering that methods and projects have been carried out and implemented that allow optimizing the combined consumption of 5G technology with the devices that intervene in the IoT, where some of these include renewable energy in order to meet the stated objectives.

\section{References}

[1] Slalmi, A., Kharraz, H., Saadane, R., Hasna, C., Chehri, A., Jeon, y G. (2019). «Energy efficiency proposal for IoT call admission control in 5G network», Proc. - 15th Int. Conf. Signal Image Technol. Internet Based Syst. SISITS 2019, pp. 396-403. https://doi.org $\underline{110.1109 / \text { sitis. } 2019.00070}$

[2] Marin, R. C., Ciobanu, R. I., Dobre, C., Mavromoustakis, C. X., Mastorakis, y G. (2017). «A context-aware collaborative model for smartphone energy efficiency over $5 \mathrm{G}$ wireless networks», Comput. Networks, vol. 129, pp. 352-362. https://doi.org/10.1016/j.comnet .2017 .06 .011 
Paper-Review of methods to reduce energy consumption in a Smart City based on IoT and 5G

[3] Uddin H. et al., (2019). «IoT for 5G/B5G applications in smart homes, smart cities, wearables and connected cars», IEEE Int. Work. Comput. Aided Model. Des. Commun. Links Networks, CAMAD, vol. 2019-Septe, pp. 1-5. https://doi.org/10.1109/camad.2019. $\underline{8858455}$

[4] Sofi, I. B., Gupta, y A. (2018). «A survey on energy efficient 5G green network with a planned multi-tier architecture», J. Netw. Comput. Appl., vol. 118, pp. 1-28. https://doi. org/10.1016/i.jnca.2018.06.002

[5] Soliman, S. S., Song, y B. (2017). «Fifth generation (5G)cellular and the network for tomorrow: cognitive and cooperative approach for energy savings», J. Netw. Comput. Appl., vol. 85, pp. 84-93. https://doi.org/10.1016/j.jnca.2016.12.005

[6] Nematchoua, M. K., Orosa, J. A., Reiter, y S. (2019). «Energy consumption assessment due to the mobility of inhabitants and multiannual prospective on the horizon 2030-2050 in one Belgium city», Energy, vol. 171, pp. 523-534. https://doi.org/10.1016/j.energy .2019 .01 .032

[7] Hui, H., Ding, Y., Shi, Q., Li, F., Song, Y., Yan, y J. (2019). «5G network-based Internet of Things for demand response in smart grid: A survey on application potential», Appl. Energy, vol. 257, n.o, p. 113972, 2020. https://doi.org/10.1016/j.apenergy.2019.113972

[8] Svahnberg, M., Gorschek, T., Feldt, R., Torkar, R., Bin Saleem, S., y M. U. Shafique, «A systematic review on strategic release planning models», Inf. Softw. Technol., vol. 52, n.o 3, pp. 237-248, mar. 2010. https://doi.org/10.1016/j.infsof.2009.11.006

[9] T. Schoormann, D. Behrens, R. Knackstedt, Fellmann, y M. (2018). «〈> design principles for supporting rigorous search strategies in literature reviews», Proceeding - 2018 20th IEEE Int. Conf. Bus. Informatics, CBI 2018, vol. 1, pp. 99-108. https://doi.org/ $\underline{10.1109 / \mathrm{cbi} .2018 .00020}$

[10] Kurk, M., Vice, E., Chief, P., y O. Officer, «Fast-forward to the future with 5G networks», p. 5.

[11] Rao S. K., Prasad, y R. (2018).«Impact of 5G Technologies on Smart City Implementation», Wirel. Pers. Commun., vol. 100, n.o 1, pp. 161-176. https://doi.org/10.1007/s11277$\underline{018-5618-4}$

[12] Batista, M., Díaz E. (2019).«Ingeniería en Telecomunicaciones 65», pp. 65-72.

[13] Zoppi, S., Kellerer, W., Schupke, y D. (2019). «Evaluation of Cellular IoT for Energyconstrained WAIC Applications», pp. 359-364. https://doi.org/10.1109/5gwf.2019 .8911660

[14] Sharma, V., Song, F., You, I., Atiquzzaman, y M. (2017). «Energy efficient device discovery for reliable communication in 5G-based IoT and BSNs using unmanned aerial vehicles», J. Netw. Comput. Appl., vol. 97, pp. 79-95. https://doi.org/10.1016/j.jnca.2017 .08 .013

[15] Al Homssi, B., Ai-Hourani, A., Chavez, K. G., Chandrasekharan, S., Kandeepan, y S. (2019). «Energy-Efficient IoT for 5G: A Framework for Adaptive Power and Rate Control», 2018, 12th Int. Conf. Signal Process. Commun. Syst. ICSPCS 2018 - Proc., pp. 1-6. https://doi.org/10.1109/icspcs.2018.8631733

[16] Avinash, P., Vamsi, B. K., Srilakshmi, T., Kishore, y P. V. V. (2021). «Smart Control System for Smart City using IoT», Int. J. Adv. Comput. Sci. Appl., vol. 12, n.o 2, pp. 408-414. https://doi.org/10.14569/ijacsa.2021.0120251

[17] Liu, Y., Yang, C., Jiang, L., Xie, S., Zhang, y Y. (2019). «Intelligent Edge Computing for IoT-Based Energy Management in Smart Cities», IEEE Netw., vol. 33, n.o 2, pp. 111-117. https://doi.org/10.1109/mnet.2019.1800254 
[18] Farris, I., Orsino, A., Militano, L., Iera, A., Araniti, y G. (2018). «Federated IoT services leveraging 5G technologies at the edge», Ad Hoc Networks, vol. 68, pp. 58-69. https://doi.org/10.1016/j.adhoc.2017.09.002

[19] Kumar, A., Krishnan, y P. «Performance analysis of RoFSO links with spatial diversity over combined channel model for $5 \mathrm{G}$ in smart city applications», Opt. Commun., vol. 466, n.o, p. 125600, 2020. https://doi.org/10.1016/j.optcom.2020.125600

[20] Boubakri, W., Abdallah, W., \& Boudriga, N. (2018, July). An optical wireless communication based 5G Architecture to enable smart city applications. In 2018 20th International Conference on Transparent Optical Networks (ICTON) (pp. 1-6). IEEE. https://doi.org/10.1109/icton.2018.8473657

[21] Ullah, Z., Al-Turjman, F., Mostarda, L., Gagliardi, y R. (2020). «Applications of Artificial Intelligence and Machine learning in smart cities», Comput. Commun., vol. 154, n.o March, pp. 313-323. https://doi.org/10.1016/j.comcom.2020.02.069

[22] Mantuano, E. S., García-Quilachamin, W. X., Santana, y J. A. (2021). «A Systematic Review of Algorithms in People Images Detection Based on Artificial Vision Techniques for Energy Management in Air Conditioners», Int. J. online Biomed. Eng., vol. 17, n.o 1. https://doi.org/10.3991/ijoe.v17i01.17899

[23] Affum, E. A., Agyekum, K. A. P., Gyampomah, C. A., Ntiamoah-Sarpong, K., Gadze, y J. D. (2021). «Smart Home Energy Management System based on the Internet of Things (IoT)», Int. J. Adv. Comput. Sci. Appl., vol. 12, n.o 2, pp. 722-730. https://doi.org/ 10.14569/ijacsa.2021.0120290

[24] Al-Mutawa R. F., Eassa, y F. A. (2020). «A Smart Home system based on internet of things», arXiv, vol. 11, n.o 2, pp. 260-267.

[25] Sanfilippo F., Pacchierotti, y C. (2018). «A wearable haptic system for the health monitoring of elderly people in smart cities», Int. J. Online Eng., vol. 14, n.o 8, pp. 52-66. https://doi.org/10.3991/ijoe.v14i08.8571

[26] Joshi, B. (2019). «Breaking the energy curve: why service providers should care about 5G energy efficiency».

[27] Series, M. (2020). «Minimum requirements related to technical performance for IMT-2020 radio interface (s)», vol. 0 .

[28] Gao, W., Ma, L., \& Chuai, G. (2017). Energy efficient power allocation strategy for 5G carrier aggregation scenario. EURASIP Journal on Wireless Communications and Networking, 2017(1), 1-10. https://doi.org/10.1186/s13638-017-0924-1

[29] Morin E. et al., (2017). «Comparison of the Device Lifetime in Wireless Networks for the Internet of Things To cite this version: HAL Id : hal-01649135 Comparison of the Device Lifetime in Wireless Networks for the Internet of Things». https://doi.org/10.1109 laccess.2017.2688279

[30] Ikpehai, A., Adebisi, B., Anoh, y K. (2019). «Effects of Traffic Characteristics on Energy Consumption of IoT End Devices in Smart City», 2018 Glob. Inf. Infrastruct. Netw. Symp. GIIS 2018, pp. 1-6. https://doi.org/10.1109/giis.2018.8635744

[31] Abdennahder, I., Rodriguez, I. B., Jmaiel, y M. (2018). «A decision approach for energy distribution management in smart cities», Proc. ACM Symp. Appl. Comput., pp. 16681673. https://doi.org/10.1145/3167132.3167310

[32] Aleksic, A., Ljepava, N., Ristic, y M. (2019). Smart Technologies and Innovation for a Sustainable Future. Springer International Publishing.

[33] Dzogovic, B., Santos, B., Noll, J., Do, V. T., Feng, B., Van Do, y T. (2019). «Enabling smart home with 5G network slicing», 2019 IEEE 4th Int. Conf. Comput. Commun. Syst. ICCCS 2019, pp. 543-548. https://doi.org/10.1109/ccoms.2019.8821727 
[34] Buzzi, S., Chih-Lin, I., Klein, T. E., Poor, H. V., Yang, C., Zappone, y A. (2017). «A survey of energy-efficient techniques for $5 \mathrm{G}$ networks and challenges ahead», IEEE J. Sel. Areas Commun., vol. 34, n.o 4, pp. 697-709. https://doi.org/10.1109/jsac.2016.2550338

[35] Yu, W., Xu, H., Hematian, A., Griffith, D., Golmie, y N. (2017). «Towards energy efficiency in ultra dense networks», 2016 IEEE 35th Int. Perform. Comput. Commun. Conf. IPCCC 2016, n.o 978. https://doi.org/10.1109/pccc.2016.7820622

[36] Yang, C., Li, J., Guizani, Anpalagan, A., Elkashlan, y M. (2018). «Advanced spectrum sharing in 5G cognitive heterogeneous networks», IEEE Wirel. Commun., 23(2), pp. 94101. https://doi.org/10.1109/mwc.2016.7462490

[37] Scopelliti, P., Araniti, G., Muntean, G. M. and, Iera A. (2017). «Mobility-aware energyquality trade-off for video delivery in dense heterogeneous networks», IEEE Int. Symp. Broadband Multimed. Syst. Broadcast. BMSB, vol. 2017-July, 2017. https://doi.org/ $\underline{10.1109 / \mathrm{bmsb} .2016 .7521921}$

[38] Salh, A., Shah, N. S. M., Audah, L., Abdullah, Q., Jabbar, W. A., Mohamad, y M. (2020). «Energy-Efficient Power Allocation and Joint User Association in Multiuser-Downlink Massive MIMO System», IEEE Access, vol. 8, pp. 1314-1326. https://doi.org/10.1109/ access.2019.2958640

[39] Joung, J., Ho, C. K., Adachi, K. y S. Sun, «A Survey on Power-Amplifier-Centric Techniques for Spectrum- and Energy-Efficient Wireless Communications», IEEE Commun. Surv. Tutorials, vol. 17, n.o 1, pp. 315-333, 2018. https://doi.org/10.1109/comst. 2014.2350018

[40] Ngo, H. Q., Larsson, E. G., Marzetta, T. L. (2017). «Energy and spectral efficiency of very large multiuser MIMO systems», IEEE Trans. Commun., vol. 61, n.o 4, pp. 1436-1449. https://doi.org/10.1109/tcomm.2013.020413.110848

[41] Lv Z., Li, Y. (2018). «Compressive sensing based channel estimation for high-order MIMO systems», Int. J. Online Eng., vol. 14, n.o 7, pp. 30-44. https://doi.org/10.3991/ ijoe.v14i07.8218

[42] Mu J., Han, L. (2017). «Performance analysis of the ZigBee networks in 5 G environment and the nearest access routing for improvement», Ad Hoc Networks, vol. 56, pp. 1-12. https://doi.org/10.1016/j.adhoc.2016.10.006

[43] Vivekanandan, M., \& Sastry, V. N. (2020), «BIDAPSCA5G: Blockchain based Internet of Things (IoT) device to device authentication protocol for smart city applications using 5G technology», Peer-to-Peer Netw. Appl., 2020. https://doi.org/10.1007/s12083-020-00963$\underline{\mathrm{W}}$

[44]Äzam, S. K., Islam, M. S., Hossain, A. K. M. Z., \& Othman, M. (2020). «Monopole antenna on transparent substrate and rectifier for energy harvesting applications in 5G», Int. J. Adv. Comput. Sci. Appl., vol. 11, n.o 8, pp. 84-89. https://doi.org/10.14569/ijacsa. $\underline{2020.0110812}$

\section{$7 \quad$ Authors}

Julieta Evangelina Sánchez Cano. PhD International Economics and Development, Complutense University of Madrid, Spain. Member of the National System of Researchers at CONACYT, México. Professor at the Faculty of Economics, Accounting and Administration of the Universidad Juárez del Estado de Durango from 2009 to date, has taught subjects related to economics and is part of the professors of the $\mathrm{PhD}$ Organization Management in the National Quality Graduate Program of CONACYT. She has been O'Gorman Scholar at ILAS Columbia University, 2013; 
and Visiting Scholar at ILAS, Columbia University 2015, making research in the topics of Energy. Member at SENESCYT, Prometeo Senior Researcher 2014-2015, Ecuador. She has a long history of applied research in topics of the Energy Sector with more than 60 publications, in books and journals internationally (julieta.san2009@ujed.mx).

Washington Garcia Quilachamin. Received the degree of magister in Informatics Management and New Technology in University Technical Federico Santa Maria of Chile (2008), Campus Guayaquil, Ecuador. He is currently pursuing a Ph.D. in System engineering degree with the National University of San Marcos, Lima, Peru. Fulltime Professor of computer science in the Faculty of Electric Engineering at the Universidad Laica Eloy Alfaro de Manabí, Ecuador. member of ISOC-Cap.Ec. Research member accredited with REG-INV-18-03232, by the secretary of higher education, science, technology, and innovation (SENESCYT), Ecuador. His research papers have been presented at conferences and published in journals internationally (scopus, springer). Referee of research for national and international scientific journals, conference proceedings. His research activity is related to the Internet of Things, Cloud Computing, intelligence systems, image processing, pattern recognition, control automatic, security, surveillance, and intelligent networks, particularly oriented to management in energy efficiency.

Jonny Pérez-Véliz. Received the degree in Systems Analyst from the Universidad Laica Eloy Alfaro de Manabí, Ecuador and the degree of magister in Informatics Management and New Technology in University Technical Federico Santa Maria of Chile (2008), Campus Guayaquil, Ecuador. He is currently a full Professor of Computer Science at the Universidad Laica Eloy Alfaro de Manabí, Ecuador. His research activity is related to information systems, IT governance, protection of personal data and privacy (jonny.perez@uleam.edu.ec).

Jorge Herrera-Tapia. Received the degree in Computer Systems Engineering from the Universidad Técnica de Norte, Ecuador in 1999, and the master's degree in Computer and Network Engineering, and Ph.D. degree in Computer Science from the Universitat Politècnica de València (UPV), Spain, in 2015 and 2017, respectively. He is currently a full Professor of Computer Science at the Universidad Laica Eloy Alfaro de Manabí, Ecuador. His research activity is related to green-electric engineering, mobile wireless data systems design, modeling, simulations, and implementations, IoT, particularly oriented to opportunistic wireless networks.

(jorge.herrera@uleam.edu.ec)

Kelvin Atiencia Fuentes. Is currently a student assistant researcher in the Faculty of Electric Engineering at Laica Eloy Alfaro of Manabí University, Manta, Ecuador. Her research activity is related to automation control systems, project management, photovoltaic system and particularly to oriented management in energy efficiency. obtained the title of technician in Installations of Electrical Equipment and Machines in 2016 (atienciafuentes@gmail.com).

Article submitted 2021-05-01. Resubmitted 2021-06-05. Final acceptance 2021-06-06. Final version published as submitted by the authors. 